\title{
La Cofradía de Mareantes de San Telmo en Las Palmas de Gran Canaria: proyecto de un montepío textil (1781-1805)
}

Antonio de Bethéncourt Massieu *

Las Palmas de Gran Canaria en 1785 era una población marítima que se aproximaba a los diez mil habitantes. Jugaba papel destacado en la misma un colectivo que dedicaba sus actividades a la pesca en la Costa de África. Los dedicados a esta faena y salazón se encontraban agrupados en torno a la Cofradía de Mareantes de San Telmo.

El «salado», muy rico en proteínas, se había convertido en alimento básico y común de la dieta de los habitantes del archipiélago, e incluso de los maderienses. Su aceptación fue tal que desde los inicios del siglo XVIII desplazó primero y erradicó más tarde en las islas el consumo de bacalao, arenques y sardinas provenientes del exterior ${ }^{1}$. El producto de su tráfico llegó a alcanzar el valor de los cien mil pesos al año. La

* Catedrático Emérito y director del SEHIC.

1 Sobre los intentos de la Económica de Amigos del País de Las Palmas en conservar las sardinas y arenques de las aguas del archipiélago, todavía poco faenadas por entonces por desconocerse en las islas las artes adecuadas, A. BETHÉNCOURT MASSIEU: "El abastecimiento de pescado fresco en Las Palmas de Gran Canaria a fines del siglo XVIII", Stvdia Historica-Historia Moderna (Salamanca). En prensa. 
pesca constituía, sin lugar a dudas, el primer renglón económico de Gran Canaria $^{2}$.

Aunque la cita sea en exceso extensa, merece la pena conocer la valoración del coronel Rocha:

«...tan asi, que en las ocasiones de que por casualidad de contrarios vientos se retarda la venida de dichos Bajeles y entrada de sus cargazones de Pesca de Salado, se ven los vecinos de las capitales de esta Ysla y la de Tenerife, y la de los diversos pueblos menores de campo, que componen sus recintos, en suma estrechez y aflición por ser alimento que diariamente usan, escaseando mucho el Pescado Fresco en sus Puertos, y Mares y lo más es costumbre inalterable en que se halla la mayor parte de las Yslas del uso de dicho abasto con que se mantienen los labradores pobres y ricos, Hornaleros y en gran número de menestrales y aún gente de otra condición» ${ }^{3}$.

\section{LA COFRADÍA DE MAREANTES}

Los pescadores que venían faenando en el banco canario-sahariano se agruparon en los años finales del seiscientos en la Cofradia de San Telmo. Al compás del éxito, la hermandad fue creciendo. En la década de los ochenta del siglo XVIII contaba entre veinte y veintidós bergantines. Cada uno, según sus dimensiones, albergaba una tripulación entre veinticinco y cuarenta hombres, tan hábiles marineros como pescadores. La cifra que alcanzaban era la de seiscientos. La práctica de la pesca les enseñaba la navegación, por lo que no era extraño acabaran enrolados

${ }^{2}$ Eguíluz al Rey, Canaria, 15.7.786. Archivo Histórico Nacional (AHN), Consejos, leg. 2448/4. A. BETHÉnCOURT MASSIEU: "Aproximación a la Economía de las Islas Canarias (1770-1808), Revista de la Universidad Complutense, Homenaje al profesor Pabón, n. ${ }^{\circ} 112$, 1978, pp. 186-202, pp. 195-96. El dato lo corrobora el Ayuntamiento o Cabildo de Las Palmas, solicitando de Carlos III autorización para fundar tres nuevas poblaciones en el S.W de la isla. Canarias, s.f. AHN, Consejos, Leg. 4061/3. y A. Millares TORRES: Historia General de las Islas Canarias. Las Palmas, 1882-1892. 10 tms. VI, 51.

${ }^{3}$ Información testimoniada abierta por don José de la Rocha, coronel de milicias y síndico personero. Canaria, 9.12.786. Aseveración que confirman los testigos en la respuesta al punto $6 .^{\circ}$ Canaria 26.11.86. AHN, Consejos, Leg. 2448/4. La noticia de la existencia del expediente la da S.F. BONNET. 
en las tripulaciones de las embarcaciones que practicaban el comercio con América. Por otro lado, la actividad pesquera implicaba la construcción, carena y reparación de los bergantines ${ }^{4}$, el fornacimiento de los mismos, consumo de efectos navales, así como de grandes cantidades de sal. No es, por lo tanto, de extrañar que los interesados en la pesca y sus familias, junto a los puestos de trabajo inducidos por dicha actividad, alcanzaran a la tercera parte del vecindario de la ciudad ${ }^{5}$.

\section{LA COMPAÑÍA}

Desde sus inicios la cofradía funcionaba de la siguiente manera. El dueño y armador de cada una de las embarcaciones junto con su tripulación constituían "una especie de sociedad comercial», una "compañía", en la que «iban al interés común y a la parte». El dueño jugaba como socio capitalista: ponía el barco y los aparejos necesarios para una navegación segura y una pesca abundante, adelantando el fornacimiento de víveres, sin llevar por ello interés alguno. La tripulación aportaba su esfuerzo como marineros y pescadores. Quedaban clasificados en «marineros", "grumetes" y "pajes de escoba». Participaban en los beneficios en función de su grado, pero también de su habilidad y rendimientos, méritos éstos que calibraba el «mandador». Ésta era la autoridad suprema en materia de faenas extractivas, mientras el "patrón» la ejerce en cuanto a la navegación se refería ${ }^{6}$.

El valor de la pesca se dividía en «soldadas", calculadas en función de los cahíces de sal empleados. El dueño recibía las que le correspondieran por el riesgo expuesto como capitalista y beneficios. La tripulación en virtud de su calificación y grado recibiría o bien una "soldada entera" o "media", una "cuarta» o «media cuarta». Los tripulantes quedaban obligados a reintegrar a su armador la parte correspondiente en la «bar-

${ }^{4}$ S.F. Bonnet: "La Confraternidad de Mareantes de San Telmo, en Gran Canaria», El Museo Canario, n. ${ }^{\circ}$ 21-22, 1947, p. 13-25. A. BethénCOURT MASSIEU: «La pesca en la Costa de África a la luz de la Real Cédula de 1770 sobre vagos y delincuentes en Canarias», II Aula Canarias y el Noroeste de África (1986). Las Palmas, 1988, p. 363-370 y «Vagos, y régimen penitenciario en Canarias. Real Cédula de 1770", Anuario de Estudios Atlánticos, 32,1986 , p. $447-487$, p. $472-3$.

${ }^{5}$ Puntos 1 y 2 de la Información testificada, ya citada.

${ }^{6}$ Punto 4 de id. y declaración de Juan Antonio Gómez. 
cala», -o sea, la parte proporcionada consumida en su alimentación, vestido y aparejos, que constituían también un fondo común-, así como devolver el adelanto recibido para el sostenimiento de su familia durante la «zafra» 7 .

El manejo de la "Compañía» obligaba al dueño de la embarcación a llevar una contabilidad minuciosa e individualizada. Naturalmente las cuentas eran anotadas por un "contador" profesional que designaba la Junta del Gremio. Eran aprobadas una por una en la Junta General celebrada por Pascua de Resurrección, coincidiendo con el fin de la zafra ${ }^{8}$.

\section{RÉGIMEN INTERNO DE LA COFRADÍA}

En esta Junta General cada hermano, propietario o mareante, ingresaba el 3 por 100 de sus beneficios, que depositaba en el "arca de tres llaves". Fondo que se destinaba mitad por mitad al culto en honor de San Pedro Telmo, desarrollado con todo esplendor en su ermita, y a la atención de asistencia social de los hermanos en caso de fallecimiento, incapacidad o enfermedad ( arca de entierros").

De los fondos depositados en ella recibía la familia del fallecido cincuenta pesos para los gastos de entierro, que cubrían además la cera «y en lo que se regulaba todo el funeral». La misma cantidad se percibía por muerte de la esposa e hijos de más de 18 años, y sólo veinticinco por los menores de edad. Anualmente se celebraba, además, un solemne funeral por todos los socios fallecidos. Para tener derecho a tales percepciones el cofrade debería haber aportado al arca de «entierros» cincuenta pesos, bien a su ingreso o con sus depósitos anuales ${ }^{9}$.

7 Loc. cit.

${ }^{8}$ Declaración de Juan Antonio Gómez en documento citado.

9 «...y si no pagó de pronto de dicha cantidad, se le llevaba en quenta la que le corresponde anualmente del uno y medio por ciento y lo que ganó su padre y abuelo, si fue contribuiente, hasta completarlo...; pero si muere antes de verificarse el cumplimiento, solo se le suministra lo que contribuio según la parte que hubo en la Compañia". Montepío... a beneficio de la Congregación de Mareantes de... San Thelmo...". Canaria, 20.3.784. AHN, Leg. 2448/4. 
En caso de invalidez por vejez, enfermedad, accidente el cofrade era socorrido con una limosna que no era fija, sino que estaba en dependencia del "sobrante», grado de inutilidad y aportaciones realizadas por el socorrido y sus ascendientes.

Finalmente, el arca poseía otros fines como la dotación de doncellas, sostenimiento de una escuela y la muy importante de seguro para los barcos. Si alguna embarcación se perdiera o sufriera graves averías, el dueño estaba capacitado para recibir un préstamo proporcionado, con calidad de reintegro y afianzamiento hipotecario ${ }^{10}$.

Todo este entramado socio-económico así como la administración del culto en la ermita estaba al cuidado y bajo la administración del "mayordomo". Percibía cincuenta pesos al año de salario y solía tener en su poder de doscientos a trescientos pesos para hacer frente a las necesidades.

La cofradía, por otra parte, dirimía sus desavenencias y pendencias internas al margen de la jurisdicción ordinaria. Las cuestiones eran llevadas ante el Capitán del Puerto, - buen conocedor de la dinámica de la Hermandad, pues solía pertenecer a la misma-, que actuaba como juez particular. Éste no les bastaba y aspiraban a tener un oidor como "Juez conservador», "con jurisdicción privativa», buscando celeridad y baratura ${ }^{11}$.

Gobernábase la cofradía mediante acuerdos tomados por mayoría entre doce diputados que formaban su «Junta Particular». Integraban ésta propietarios de uno o más embarcaciones, elegidos en la «Junta General". Las vacantes que iban produciéndose por fallecimiento, incapacidad notoria $u$ otra causa de fuerza mayor, se suplian por otros propietarios de parecidas condiciones ${ }^{12}$. Los acuerdos eran asentados en el libro de actas por un asalariado, puesto que generalmente desempeñaba el escribano más antiguo del Cabildo.

Los acuerdos eran de suma importancia, pues la cofradía desde su fundación carecía de estatutos y aprobación de alguna autoridad civil o eclesiástica.

10 J.A. Álvarez RIxo: Cuadro histórico de estas /slas Canarias... de 1788 a 1812. Las Palmas de Gran Canaria 1955, I, 12.

11 Punto 9 de la Información ya citada.

12 Montepio... a beneficio, citada. 


\section{INDICIOS DE UNA CRISIS}

Aunque a la altura de la década de los setenta el nivel alcanzado por el gremio de mareantes era a todas luces floreciente; sin embargo, el rastreo en la documentación permite constatar que alcanzado su cenit, en el interior de la institución se denotan algunos síntomas, aún leves, de una posible crisis.

El trabajo duro de la vida a bordo y la separación prolongada de sus familias no compensaban, ya que los ingresos «apenas alcanza lo más preciso para su modesto vestuario que usan", nos dice el corregidor Eguiluz. Ocupaban viviendas muy modestas e insuficientes en los riscos. Como por oficio tienen la mar y esta vida genera un espíritu de aventura, no es extraño que para superar las dificultades domésticas emprendan el camino de las Indias,

«dejando abandonadas a sus mujeres e hijos, todos sin abrigo, expuestos a las miserias que produce de suyo la flaqueza humana» ${ }^{13}$.

A los motivos de tipo económico para emigrar, se añadian las prolongadas ausencias de estos hombres, que acarreaban la vida de holganza de sus mujeres, que no ayudaban al sostén de sus familias, «largas en lo general, como país fecundo" que es el Archipiélago ${ }^{14}$.

Al lado de la vida difícil, la emigración y la holganza, tenemos otro síntoma en la indisciplina que se había introducido entre las tripulaciones desde no mucho tiempo atrás. Algunos pescadores:

«Se intrometen en el buen régimen y gobierno, no profesan aquella subordinación que antes tenían a sus patrones y Mandadores, a los que faltan el respeto" ${ }^{15}$.

13 Eguíluz al Rey, Canaria, 15.7.786. Leg. citado.

14 Documento citado.

15 Punto $3 .^{\circ}$ de la Información y testimonio de Bartolomé Benito Hervás... Ya citada. 
Y lo que era peor, obtenían el anticipo al alistarse y luego se negaban a embarcar, lo que producía perjuicios a la «Compañía" ${ }^{16}$. No taltaban tampoco las críticas sobre liquidación de cuentas y valor de la "soldada". Alguno comenzó a mostrarse partidario de ejercer el oficio como asalariado o navegar, incluso, en aparcería, recibiendo las tripulaciones la «media» e incluso la "cuarta" de los beneficios ${ }^{17}$.

\section{NACE LA IDEA DEL MONTEPÍO}

La carencia de una industria en el archipiélago, los problemas detectados en el seno de la cofradía de mareantes y la existencia de unos miles de pesos depositados en el «arca de tres llaves», hizo brotar en la mente del corregidor José de Eguíluz la idea de organizar con los miembros de la hermandad un montepío destinado a tejer lana y elaborar efectos navales. Mediante el trabajo de las familias de los mareantes cesaría el ocio de las mujeres e hijas. $Y$ al paso obtendrían ropa barata y un beneficio por su trabajo, con que ayudar al sostén de la familia ${ }^{18}$. $Y$, finalmente, serviría el montepío de núcleo inicial y modelo que permitiera la industrializaciór de la isla, en caso de un resultado positivo.

En 1781 para llevar adelante su idea, Eguíluz la pone en conocimiento del Consejo de Castilla. Pero éste se redujo a agregar la propuesta al expediente sobre la pesca en Canarias. Integraban éste, el proyecto de establecimiento de una compañía para la pesca de ballenas y una solicitud de la económica del País de Las Palmas sobre el fomento de la pesca del ribera y supresión de la postura municipal ${ }^{19}$. Ante la reiterada insistencia del Corregidor, la Sala de Gobierno aprobaba en 1

\footnotetext{
${ }^{16}$ «...y al testigo - nos dice Antonio Quintana- en bastantes ocasiones le pasó el chasco, cuando era mandador, por iguales acciones andar tras ellos para hacerles cumplir». LOC. cit.

17 Punto 9 de la Información citada.

${ }_{18}$ «...del caudal sobrante del Gremio se surtirá (el Montepío) de primeras materias de lino, lana, cáñamo y algodón, y se distribuirá entre familias de los mareantes pobres para que sirviera de ocupación de mujeres e hijas, preservándolas de la ociosidad y escasez en que viven, encontrando a precio cómodo lo que necesitan para su vestido y utensilios para la navegación y pesca». El personero al Consejo. Canaria, 10.2.787. Leg. citado.

t9 Ver nota 1.
} 
de febrero de 1782 la idea y anima a Eguíluz para que lleve adelante el proyecto,

«pero no hubo efecto, aunque se practicaron varias diligencias, porque no estaban de acuerdo los principales del gremio» ${ }^{20}$.

Sin embargo, no cejó en el intento, tanto que el Consejo de Castilla acabó enviándole una segunda misiva, en la que le encarecía llevara adelante el proyecto. Orden que le fue remitida el 20 de julio, junto con otra dirigida a la Audiencia para que prestara el máximo apoyo a la empresa ${ }^{21}$.

Con el beneplácito de Madrid Eguíluz fue convenciendo a los elementos de más peso y luces de la cofradía, utilizando la carta del Consejo "con alguna viveza" ${ }^{22}$. Entre sus interlocutores se contaban Bartolomé Morales, lldefonso de Santa Ana y José Flores. El 30 de septiembre acuerdan llevar adelante el «proyecto, de la mayor utilidad para el gremio" y el 5 de octubre, bajo la presidencia del Corregidor, se celebra una Junta General extraordinaria en el salón de la ermita de San Telmo a las tres y media de la tarde ${ }^{23}$.

\section{NEGOCIACIÓN DEL MONTEPIOO}

Se trató en la misma sobre la conveniencia de constituir por los agremiados un montepío para hilar y tejer diversas fibras. Labor que realizarían las mujeres e hijas de los mareantes, con alivio de sus casas y

20 Informe del personero, ya citado.

21 Pedro Escolano a José Eguíluz, Madrid 26.7.783 en «Expediente formado en virtud de RO de SM a representación del Corregidor de Canaria Don Joseph Eguíluz, sobre establecimiento de un Montepío de Mareantes". AHN Consejos, Leg. 2248/4. La primera noticia de la existencia de este expediente la da Sergio F. Bonnet en el artículo citado, $p$. 14. Se la había transmitido Antonio Rumeu de Armas. Al que denomina Proyecto de Eguíluz dedica exactamente una página, cfr. artículo citado, p. 21-22.

${ }_{22}$ Eguíluz al Rey, Canaria 15.7 .786 y calificación del escribano Juan Reyes Cabrera. Canaria 30.9.783.

${ }_{23}$ Acta de la Junta General, ya citada. 
vestidos y aparejos a precios razonables. Por unanimidad fue aprobado estudiar la propuesta y contestar por escrito. Advirtieron al Corregidor que no existía en el «arca» el caudal "que se creía». Le instaron para que lo comprobara, a lo que se opuso Eguíluz. En total había algo más de tres mil pesos en efectivo ${ }^{24}$.

Un mes más tarde los diputados Bartolomé Morales e Ildefonso de Santa Ana presentaban la contrapropuesta. En ésta perfilaban objetivos y exponían la situación de la cofradía, sin ocultar los inconvenientes advertidos. Reducían la oferta de la cofradía al sobrante del «arca de tres llaves" donde ingresaban el 3 por 100 de lo que producían los barcos y «soldadas», así como el de las embarcaciones dedicadas a la pesca de ribera, que no representaba cantidad sustanciosa. De los tres mil pesos sobrantes depositados en el arca, cuatrocientos se hallaban comprometidos para el dorado de los tres retablos; además, existía acuerdo de adquirir dieciocho candelabros de plata para el servicio de los altares, pues los antiguos habían sido fundidos para fabricar la lámpara de plata que colgaba en la ermita. Era obligado reservar 1.200 pesos para hacer frente al gasto ordinario del año: entierros y dote de doncellas. Por tanto, la cifra que podían destinar a la adquisición de materias primas y utillajes quedaba reducida a mil pesos ${ }^{25}$. Para el futuro ofrecían la tercera parte de los ingresos, siempre que contribuyeran a los mismos «los barquitos de Telde y Galdar».

Grave inconveniente era la carencia de materias primas en las islas. No se producía cáñamo y era muy corta la cosecha de lino. La lana abundaba, pero la producida se consumía totalmente por los telares de Gran Canaria, que aún importaban la sobrante de Fuerteventura. La adquisición de lana insular por el montepío acarrearía la ruina de los telares de Arucas, Teror, Galdar... que fabricaban tejidos, sombreros y «burel» de uso general entre los campesinos. Era dura la disyuntiva porque «degenerando la polícia, cuando para el fomento de un pueblo, se destruían otros de la misma provincia» ${ }^{26}$.

Sin embargo estaban muy interesados en el montepío,

24 Loc. cit.

${ }_{25}$ Morales y Santana a Eguíluz, Canaria 31.7.783. Leg. citado.

26 «...sin verificarse que salga de las yslas una libra de lana, ante sí, se conduce a ella (GC) la sobrante de la ysla de Fuerteventura; por manera que no puede decirse que hay primeras materias en la Ysla». Doc. citado. 
"por preferirse sus mujeres e hijas en las iladas y otros exercicios compatibles a su sexo, con que separadas de la inacción en que muchas de ellas viven durante la tarea de sus maridos, hijos y hermanos, sean útiles al estado y a sus propias casas y familias" ${ }^{27}$.

Como solución proponen la importación de lana peninsular, siempre que los derechos de entrada sean rebajados, para que los tejidos salgan a precio competitivo con los géneros importados y de calidad semejante.

Con lana tejerían "cordoncillo" y "jerga", telas que usan en todas las estaciones los mareantes y sus hijos. Tampoco podía descuidarse otros productos derivados del lino, cáñamo y algodón, tan útiles para el consumo de las embarcaciones ${ }^{28}$.

Cuatro meses y medio tardó Eguíluz en redactar el proyecto de Estatutos o Reglamento del Montepío de la Cofradía de mareantes de San Telmo ${ }^{29}$.

\section{REGLAMENTO DEL MONTEPIO}

El proyecto redactado por Eguíluz es un documento clave, minucioso en extremo y en el que trata de prever todas las contingencias. Es muestra de la enorme capacidad de este corregidor, así como de sus profundos conocimientos sobre organización empresarial. Tiene el autor grandes esperanzas puestas en llevarlo adelante y para ello trata en su texto de salir al paso de objeciones y al tiempo deslumbrar de antemano a quienes por oficio deberían actuar cual «abogado del diablo».

De sus 61 artículos, 30, o sea el 50 por 100, constituyen el capitulo cuarto, parte dedicada a la administración del montepío. Los 19 de la tercera, al destino de los beneficios y los 12 restantes se reparten entre

${ }^{27}$ Doc, cit.

28 LOC. cit.

${ }_{29}$ Montepío... a beneficio de la Congregación de Mareantes de San Thelmo ya citada. El proyecto de Reglamento consta de un largo capítulo preliminar, y cuatro capítulos o partes, que encierran 61 artículos. 
los dos primeros capítulos, destinados a la dotación y aplicación de los fondos corporativos. Todo ello precedido de un largo capítulo preliminar en que se exponen los fines de la institución.

$\mathrm{Si}$, como vimos, tenemos en cuenta que el colectivo de mareantes con sus familiares, más los puestos de trabajo inducidos, representaba la tercera parte de la población de Las Palmas, el intento de Eguíluz de actuar sobre el mismo en una línea muy ilustrada: preservarlo de la ociosidad y transformar gran parte del mismo en personal útil a la sociedad y a sus propias casas, que precisamente no gozaban de un nivel desahogado. Fragilidad que aumenta en caso de enfermedad, accidentes de mar y paro estacional, bien por mal tiempo, carena o reparación de las embarcaciones ${ }^{30}$. Y esta «reforma», mediante un proceso de industrialización, sector del que carecían las islas, que sirviera de acicate y modelo, y al tiempo germen de una posible expansión.

\section{FINANCIACIÓN}

El capital para la puesta en marcha se reducía a 1.000 pesos de a 15 reales, o sea la tercera parte de los fondos depositados en el «arca de tres llaves». A partir del primero de enero de 1784 se incrementaría anualmente con la tercera parte de las entradas totales de la cofradía. Recuérdese que era obligación ingresar el 3 por 100 de los beneficios de los armadores y de los mareantes. Los otros dos tercios se destinaban por mitad al culto en la ermita y a los fines del «arca de entierro" ${ }^{31}$.

Este capital se vería incrementado con un 6 por 100 que se ha de cargar sobre el precio de costo de las materias primas adquiridas y en el precio de venta de los tejidos y efectos navales elaborados por el montepío. Este incremento - como veremos - estaba destinado a sufragar los gastos del almacén, administración y distribución, así como a la remuneración del depositario ${ }^{32}$. Finalmente, el montepío podria recibir man-

\footnotetext{
${ }^{30}$ Cap. Il, art. 1 y A. BethénCourt MASsieu: «La pesca en la costa...» página citada.

31 I, 4.

32 Infra, p. 260.
} 
das, legados y donaciones, tanto de los cofrades, como de particulares. En ello había esperanzas dado el carácter eminentemente benéfico-social de la institución ${ }^{33}$.

Alcanzar un fondo de diez mil pesos era objetivo prioritario si se pretendía un buen desenvolvimiento de la empresa. Por ello no podría desmembrarse este capital, salvo en los casos de fuerza mayor: epidemia, incendio del templo o robo sacrílego de sus alhajas. El montepío acudiría con largueza ante estas desgracias, pero con obligación de reintegro por el recipiendario ${ }^{34}$. Este fondo de diez mil pesos, como es natural, no se reducía a dinero contante, sino que quedaba integrado por el valor de las materias primas almacenadas y géneros manufacturados.

\section{OBRA SOCIAL}

Las utilidades estaban destinadas en beneficio de los agremiados, favoreciendo siempre a los más pobres y aplicados a la pesca y el tráfico. Se socorrería la invalidez, vejez y enfermedad, con pensiones entre dos y cuatro pesos mensuales, en función de los años que cada uno hubiera contribuido y la calidad de su esfuerzo. Incluso, los enfermos temporales podrían recibir una "ayuda de costa", pero por una sola ve? ${ }^{35}$.

Atención especial recibirían las viudas y aún más en el caso de quedarles infantes a su cargo e hijos en edad de aprender oficio. La pensión de éstas sería semejante a las de los hombres, atendiendo a los méritos de su marido y al "sobrante» del montepío ${ }^{36}$. Si la viuda no alcanzaba los treinta años y pretendiera contraer nuevas nupcias, recibiría como dote y por una sola vez cincuenta pesos ${ }^{37}$.

Tampoco los hijos eran olvidados. Para la educación de los menores de diez años se dotaría una plaza de maestro y otra de maestra para las

${ }^{33}$ «...conceptuándose ésta una de las más bien entendidas y atemperadas a la religión y bien común de la ciudad" I, 5 . Nótese de paso la mentalidad religiosa y a la par ilustrada de un hombre tan de su siglo como Eguíluz.

${ }^{34}$ II, 2.

35 III, 3.

${ }^{36} \mathrm{III}, 8$.

${ }^{37}$ Se cesa en el derecho a percibir la viudedad en caso de fallecimiento, mejora de posición o nuevas nupcias, excepto si éstas fueran con otro cofrade. 
niñas, que aprenderían además de lectura, escritura y cuentas, labores propias de su sexo ${ }^{38}$. Cumplidos los diez años aprenderían un oficio, tratando de ilustrarles para que ejercieran. Los más adelantados y dispuestos embarcarian rumbo a la Península para titularse en la «Escuela de Pilotaje», con lo que podían navegar a la Península y especialmente a Indias, que era donde se hacía el principal comercio, en manos extranjeras por aquellas fechas. Para navegar entre las islas o alcanzar la costa de África bastaba manejarse con la práctica ${ }^{39}$. En el caso de surgir un superdotado que pudiera ser útil a la comunidad como piloto o en las fábricas, se le enviaría becado a los centros más prestigiosos de la nación o el extranjero, «en donde más florezca su especialidad» ${ }^{40}$. A los huérfanos que no sintieran vocación marinera, la Junta del Montepío les buscaría maestro que les enseñara un oficio, abonando el montepío el coste del aprendizaje, vigilando su formación. Finalmente, no se comenzaría a distribuir pensiones si no al año siguiente de haber logrado acumular el capital social de los diez mil pesos ${ }^{41}$.

Pero no terminaba con la política asistencial a los mareantes el pensamiento de Eguíluz. Preveía que el montepío fuera un núcleo generador de una primera industrialización de la isla. Se proponía en un segundo paso abrir la manufacturación a otras familias de la ciudad y el campo, dando como siempre preferencia a los pobres. Proyectaba incluso pasar del domestic systeme al proceso fabril y extender la actividad a nuevos sectores como la seda y el algodón ${ }^{42}$.

\section{EL TRABAJO}

Inicialmente con el capital adquiririan lana, cáñamo y algodón. También telares y otros instrumentos. Distribuida la materia prima sería hilada

38 III, 5 .

39 III, 4.

40 III, 9 .

41 III, 11.

${ }_{42}$ «Sino a las sedas, a las que dentro de pocos años convidará el considerable número de morales que con este fin se han plantado y planta actualmente en varios pueblos a beneficio de su benigno clima, y con la del algodón, que también se va aumentando y puede con el tiempo ser motivo de rama de consumo activo..." III, 1. Queda previsto también que en caso de obtener en el futuro exceso de utilidades, pudieran dedicarse en parte al auxilio de enfermos rurales". III, 3 . 
y tejida en los domicilios, en los telares facilitados en préstamo por el montepío. La labor de cada operación estaría valorada según arancel fijado a la vista del público, así como el precio de venta del producto terminado ${ }^{43}$. Se otorgaría preferencia a la manipulación de géneros de mayor uso entre los mareantes y sus familiares: "coleta» para sábanas y camisas, "cordoncillo" y "bayeta" ordinaria para la ropa de faena; medias de lana y algodón para tiempos de descanso y «liña» para la pesca.

La puesta en marcha acarreaba al montepío la adquisición de tornos, telares, plomadas, etc. para entregar a las familias con la obligación de reintegrar su valor a lo largo de un dilatado plazo ${ }^{44}$.

Tan esencial como lo anterior sería la fabricación de lonas, cabos y cables. En el mercado de efectos navales se intentaría colocar la producción que excediera a las necesidades del gremio. Sin embargo, no siempre sería conveniente fabricar cordelería en Las Palmas, pues podía adquirirse a precios mejores en la Península o en el extranjero. Era imprescindible almacenar constantemente en el montepío un variado repuesto para casos de urgencia o guerra. Durante la última con Inglaterra se llegó a pagar el quintal a cuarenta pesos ${ }^{45}$.

\section{LOS COFRADES}

Eguiluz trató, al redactar el Reglamento, de superar algunas dificultades detectadas en el funcionamiento de la Cofradía de Mareantes de San Telmo. Con esta finalidad incluyó los artículos, del 9 al 19, en la parte tercera. Esfuerzo trascendente si tenemos en cuenta que la institución carecía de unos estatutos aprobados. Nos detendremos en ellos con brevedad ya que nos permiten conocer mejor el funcionamiento interno de la institución.

\footnotetext{
${ }^{43}$ II, 3.

44 II, 4.

45 II, 5 y 6.
} 
Estaba la cofradía integrada por dos tipos de hermanos: los «pretendientes» o «novicios» eran los que, con el abono del 1,5 por 100 de sus beneficios anuales a la "caja de entierros", no habían aún completado los cincuenta pesos que daban lugar al "derecho" a percibir la ayuda para el entierro. Los propiamente "cofrades» o "adscritos", si hubieran satisfecho dicha cantidad ${ }^{46}$. Por lo que toca a los propietarios o armadores de los barcos, al aportar el 3 por 100 anual de sus beneficios, resulta que contribuian al "arca de tres llaves" ciento cincuenta pesos ${ }^{47}$. Proponía Eguíluz que en el futuro se consideraran como «adcritos» después de contribuir durante dos años si poseyeran un barco, o al ingreso del primer año si armara dos o más.

El problema; sin embargo, era más complejo por lo que se refiere a la marineria al no resultar homogéneas las ganancias de cada uno de los tripulantes. De otro lado eran muchos los años en que se veían obligados a permanecer en situación de hermanos novicios. Todo ello obligaba a continuar con el sistema tradicional, «pues se ha observado muy equitativo a favor de los pobres» ${ }^{48}$. Propone Eguíluz tan sólo introducir una mayor flexibilidad para la recepción de las aportaciones de éstos y la posibilidad de retirarse de la cofradía con la devolución de las cuotas ingresadas ${ }^{49}$.

Para una mayor transparencia la cofradía llevaría en adelante sendos libros de registro para «novicios» y «adscritos». En aquél serían anotados anualmente las aportaciones de cada uno y en hoja correspondiente los nuevos aspirantes que entraran a servir en las compañías. Para una mayor facilidad el libro sería abecedario. También estaría permitido compleiar los cincuenta pesos en cualquier momento ${ }^{50}$. Para facilitar la labor cada armador llevaría un libro por barco o "compañía" con la cuenta individual de los tripulantes. El navegante recibiría las cuentas de su patrón, sobre las que calculaba el 3 por 100. Incluidos en el libro de registro se les irían anotando todas las incidencias del hermano hasta su muerte, haciendo constar la fecha y lugar de su enterramiento ${ }^{51}$.

46 III, 16.

47 «...que regulado por un quinquenio y hecho cómputo de un barco con otro, asciende anualmente a ciento cincuenta pesos, cuya mitad corresponde al arca de entierros» III, 14.

$48 \mathrm{III}, 15$.

49 III, 12 y 13 .

50 III, 18.

51 III, 17 y 19 . 
Semejante cúmulo de trámites tiene su efecto en las dos sesiones de la Junta General de Pascua de Resurrección. En la primera recibían noticia de la liquidación de cada compañía y de sus beneficios en la campaña, pues se le entregaba a cada uno la suya. Analizadas en casa, en la segunda podrían poner reparo, aclarar dudas y aprobar la liquidación. A renglón seguido se procedía al ingreso de las cuotas en el «arca de tres llaves".

\section{EL GOBIERNO: LAS JUNTAS}

Para la administración y gobierno del montepío fue diseñada una organización compleja, con contrapesos y controles. Iba dirigida a lograr una eficaz, sana y responsable gestión. Procuraba, sin embargo, conservar al máximo el viejo organigrama de la cofradía, pues había demostrado un alto nivel de eficacia a lo largo de casi una centuria. Funcionaría el montepío bajo la dirección de una "Junta Particular", integrada por seis miembros: tres "diputados», un "contador», un «depositario» y el "Secretario». Serían designados por la «Junta General» de la cofradía, que como ya vimos, estaba compuesta por la totalidad de los dueños de barcos dedicados a la pesca del «salado». Se reunía ésta cada tres meses en el salón levantado en la ermita de San Telmo ${ }^{52}$. Sus acuerdos eran tomados por mayoría. Era función de la «General» decidir sobre todos los asuntos de importancia que afectaran a la cofradía y acordar cada uno de los socorros a los mareantes. Si algún negocio o pensión requiriera decisión urgente, se tomaría por la «Junta Particular», pero siempre de modo provisional, "por ahora" ${ }^{53}$. Si la gravedad rebasara la competencia de la «Particular», se convocaría una General con carácter de «Extraordinaria». La General quedaba ahora facultada para introducir en el Reglamento las modificaciones que reclamase la práctica cotidiana, pero con el requisito de ser necesaria una mayoría de dos tercios ${ }^{55}$. Solía concederse receso en el transcurso de las mismas para reflexionar, ne-

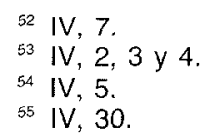


gociar y buscar las soluciones más convenientes en caso de divergencias $^{56}$.

La más importante de las juntas de este tipo era la celebrada por Pascuas de Resurrección. En las mismas se aprobaban las cuentas del culto y las operaciones verificadas sobre el «arca de entierros". Ahora se añadirían la aprobación de las cuentas del montepío, que deberían llegar a la asamblea «revisadas y adicionadas» por su Junta Particular. Como vimos, la complejidad de los acuerdos a tomar obligaba a dividirla en dos sesiones. En la primera se exponía el resultado de las cuentas y se mostraban los libros, especialmente los que llevaban los armadores para cada uno de sus barcos, así como las cuentas de cada tripulante. Las cuentas eran susceptibles de discusión. En la segunda sesión se procedía a las aclaraciones y la aprobación de las mismas ${ }^{57}$.

Como es observable el montaje del montepío sobre el esquema de la Cofradia, obedeció en palabras de Eguíluz al

"notorio celo y desinterés con que hasta aquí se ha manejado el arca de San Thelmo y sus caudales por los individuos de la Confraternidad, Amos de Barcos" ${ }^{58}$.

También en la sala de la ermita se reunirian todos los sábados últimos de mes la «Junta Particular» de montepío. Sus miembros desempeñaban el puesto por tiempo ilimitado, procurando los cofrades seleccionar para la misma a los "de generalidades más ventajosas en celo, actividad, instrucción y desinterés" ${ }^{59}$. Los acuerdos como en la General se adoptarían por "pluralidad de votos", deshaciendo en caso de empate el voto del diputado más antiguo ${ }^{60}$. La General señalaría diputados suplentes para casos de ausencias con el fin de que siempre fueran seis los votos ${ }^{61}$. También se daría la posibilidad de que la Junta

\footnotetext{
${ }^{56} \mathrm{IV}, 6$.

57 LOC. cit.

58 IV, 28.

$59 \mathrm{IV}, 1$.

60 IV, 7 .

61 IV, 8.
} 
General agregara alguna persona, dueña de barco o no, con especiales conocimientos que fuera de utilidad a la colectividad ${ }^{62}$.

\section{DIPUTADOS, DEPOSITARIO Y CONTADOR}

Por lo que toca a los directivos de la «Junta Particular» el trabajo se distribuía de la siguiente manera:

Los tres «diputados» quedarían encargados del giro, tanto para adquirir materias primas y efectos navales en la Península y el extranjero, así como el fletamiento, pólizas de seguro, operaciones de desembarco y pago de aduanas ${ }^{63}$. Las operaciones podrian realizarlas por cuenta del montepío en solitario o en sociedad con comerciantes y hombres de negocio ${ }^{64}$.

El «contador» llevaría tantos libros como géneros se trabajaran. También uno de "cargo y data", otro para las cuentas individuales y consignaciones que fueran acordadas en favor de los cofrades con el fin de conocer en cada momento a los deudores y la cuantía de los débitos, tanto frente al montepío como con el «arca de entierros» ${ }^{65}$. Los libramierıtos no serian de cuenta del contador, sino que continuaría realizándolos el "mayordomo" de la cofradía, quien los abonaba, cobrando los ingresos. Para hacer frente a estas obligaciones tendría en su poder de doscientos a trescientos pesos ${ }^{66}$.

El "secretario" además de ejercer las funciones inherentes a este cargo, podrá especial atención en llevar los libros de registro de «novicios» $y$ «adscritos».

El cargo más delicado era indudablemente el de "depositario" por su intervención en el manejo de los fondos y la imprescindible doble

\footnotetext{
${ }^{62}$ IV, 6. No tendrían voto, pero si voz.

${ }^{63}$ IV, 10.

64 IV, 9.

${ }_{65}$ IV, 13.

${ }^{66}$ IV, 14.

${ }^{67}$ IV, 13.
} 
condición de encontrarse dotado de conocimientos técnicos que le permitieran una correcta distribución de las materias primas y dirección de los procesos de elaboración con la necesaria calidad y economía ${ }^{68}$. Además estaba obligado a dar salida en el mercado a los excedentes ${ }^{69}$. Era por tanto responsable del almacén, la fabricación, comercialización y abono a los productores de las cantidades ajustadas ${ }^{70}$.

Tal cúmulo de funciones y obligaciones hacía que fuera el «depositario" el único cargo remunerado en el seno del montepío ${ }^{71}$. Mientras el capital de éste no alcanzara los seis mil pesos, cobraría cien pesos anuales, y rebasada esta cifra, doscientos. Los percibiría del recargo del 6 por 100 con que pretendían cargar el valor de los géneros adquiridos, así como sobre los productos vendidos. Con este fondo sería costeado el sostenimiento del almacén y el abono de la mano de obra ${ }^{72}$.

\section{OTROS ASPECTOS DEL FUNCIONAMIENTO}

Tanto los emolurnentos como el precio de los productos terminados estarían expuestos al público ${ }^{73}$. Esto acarreaba que el «depositario» $\|$ evara tres libros: cuenta de hilados, otro para los tejidos y el tercero con la individual de cada agremiado. Aunque todas las operaciones eran de su responsabilidad, aún quedaría sometido a la vigilancia de los dos «diputados» más antiguos, quienes estarían capacitados para visitar los talleres domiciliarios, o los locales donde trabajaran un grupo de asociados $^{74}$.

\footnotetext{
${ }^{68}$ «...pues el manejo de caudales y efectos exige de suio el maior abono, aunque supuesta la correspondiente fianza y una instrucción más que regular en las manufacturas para dar a las primeras materias todo el beneficio de que son susceptibles, según sus especies y objeto a que se dirijan». IV, 16.

69 IV, 17.

70 IV, 13

71 «...como el Depositario es de tanto peso y responsabilidad exige de suio alguna compensación, pasados dos o tres años en que el caudal del Montepío empiece a tomar vigor». IV, 28

72 IV, 24.

73 IV, 28.

${ }^{74}$ Loc. cit.
} 
El Reglamento, finalmente, regulaba con minuciosidad la distribución de las materias primas y la adquisición por agremiados y armadores de los géneros fabricados. Para garantía se exigía a cambio de las materias primas fianza o empeño de alhajas, pudiendo llegarse en caso de incumplimiento a la retención de lo adeudado por los armadores ${ }^{75}$. Tampoco es olvidado el horario del almacén y la posibilidad de los agraviados a recurrir ante los «diputados» en caso de discrepancia con el «depositario $^{76}$.

En resumen, la concepción de esta empresa centralizadora es una muestra más de la capacidad y preparación de nuestro activo corregidor.

\section{TRAMITACIÓN BUROCRÁTICA DEL PROYECTO}

Ante un prolongado silencio de más de dos años por parte del Consejo de Castilla, Eguíluz se dirige directamente al Soberano, elevando de nuevo el proyecto. El corregidor consciente

«de que el Montepío producirá considerables ventajas, no sólo al gremio de Mareantes, sino también a toda esta capital e Isla, mayormente si el depósito de Expolios y Vacantes le agrega alguna cantidad" ${ }^{77}$

el monarca. Este refuerzo del capital fundacional permitiría reducir el período de rodaje $y$, al tiempo, extender la distribución de materias primas «a los que no pueden ser incluidos en el número de los confrates» ${ }^{78}$.

Por decisión de Carlos III, el conde de Floridablanca ordenó a Rodríguez de Campomanes que procediera la Sala del Gobierno a separar el expediente del montepío del resto referente a la pesca en aguas de $\mathrm{Ca}$ narias y tramitarlo con prontitud. Al tiempo el Conde daba las mejores

75 Objetivo especial de estos Diputados era "que no se malogre el tiempo, de que depende en lo general la mayor o menor comodidad de los precios». IV, 24.

70 IV, 19, 20 y 21.

$"$ Eguíluz al Rey, Canaria, 15.7.786. Leg. citado.

${ }^{78}$ Documento citado. 
esperanzas a Eguíluz ${ }^{79}$. El Fiscal califica el proyecto de "sumamente útil y muy preciso" para conservar y aumentar la matrícula del mar en Canarias. Sin embargo, recomienda como precaución consultarlo con los Amigos del País de Las Palmas. Idea que fue tergiversada por el Consejo, al acordar que la Audiencia hiciera comparecer a cuantos se consideraran interesados en el montepio o resultaran afectados por la creación del mismo ${ }^{80}$. Equivalió a remitirle ad kalenda graeca.

Estas disposiciones se cruzaron con un memorial elevado a Carlos III por el síndico Personero del Cabildo de Gran Canaria. Adjuntaba al mismo una información testimoniada de algún interés, abierta precisamente a petición de los mareantes. En nombre de la Isla solicitaba del monarca la aprobación del montepio tal como había sido diseñado y que fuera acogido bajo patrocinio. Al igual que Eguíluz pedía una ayuda inicial sobre Expolios y Vacantes, así como que confirmara al capitán de puerto o capitán de mar, "que regularmente era de confraternidad", para que continuara ejerciendo justicia entre los del gremio en casos de poca importancia, mediante juicios orales. Los más graves deberían en el futuro ser fallados por un «Juez conservador privativo, para evitar los costes». Al juez conservador le sería encomendada una especial vigilancia sobre la disciplina de las tripulaciones, así como consentir que se pudiera enrolar un marinero con un armador, sin haber reintegrado el adelanto al anterior ${ }^{81}$. Floridablanca lo remitió a Campomanes «para que con la posible brevedad informe al Consejo" ${ }^{82}$, pero la Sala ordenó su agregación al expediente, a la espera de la opinión de la Audiencia ${ }^{83}$.

La Audiencia mantuvo silencio a pesar de una nueva requisitoria. Asombra la desidia burocrática, si no es que el Tribunal recibiera presiones en Las Palmas. Pero más asombro causa al historiador comprobar, cómo dieciséis años más tarde, o sea a fines de 1803, la Sala de Gobierno haga memoria del tema a la Audiencia, conminándola al cumplimiento de lo ordenado en el plazo perentorio de dos meses ${ }^{84}$.

${ }^{79} \mathrm{~S}$. Ildefonso, 29.9.786. Floridablanca a Campomanes y en Eguíluz. Leg. citado.

${ }^{80}$ Dictamen del Fiscal. Madrid 24.1.787. Resolución de la Sala 9.2.787. El secretario del Consejo a la Audiencia, 27.3.787. Leg. citado.

${ }_{81}$ Síndico personero al Rey, Canaria, 10.2.787. Leg. citado.

82 El Pardo, 21.3.787. Leg. citado.

${ }^{83}$ Madrid, 30.3.787. Leg. citado.

${ }^{84}$ Madrid, 23.3.803, y 4.5.803. Leg. citado. 


\section{INFORME NEGATIVO DE LA AUDIENCIA}

A la altura de 1804 pedir opinión sobre la conveniencia de crear el montepío en Las Palmas era como «pedir peras al olmo». Había transcurrido el tiempo oportuno. En Canarias, como en España, se vivía en plena crisis, pero en las islas la que venía sufriendo era secular, de larga duración. Es lógico que el cúmulo de problemas pesaran también sobre la Cofradía de San Telmo en víspera de una eminente ruina.

«Eran —nos dice al respecto Álvarez Rixo- todavía más sensibles y transcendentales, desde que fue aniquilada el arca del gremio de Mareantes ${ }^{85}$,

con el arribo en los inicios de 1805 del Comisario regio don Juan Antonio Báñez, quien acabó, en virtud de la legislación hacendística del Godoy, canjeado el valor de las propiedades en tierras de la cofradía y el depósito en el arca por ocho mil pesos en vales reales ${ }^{86}$.

En este contexto entenderemos mejor el inclemente informe denegatorio del montepío elaborado por la Audiencia, que, por otro lado, alguno de sus oidores no debió contemplar como negocio redondo en los años anteriores. Pero tampoco debemos dejar de valorar que después de una incuria de tantos años, no se hubieran acentuado los factores negativos.

La Real Audiencia aunque considera la pesca del salado renglón básico como alimento de la población insular y el único positivo ${ }^{87}$, y por tanto el primero, en la balanza económica, así como que

85. Obra citada I, 10.

${ }^{86}$ «Pero a fines de 1805 aportó a estas Yslas uno de tantos empleados de los que con pretexto de buen gobierno nos han solido mandar de Madrid a despedazarnos las entrañas: que asi puede decirse de quien destruye lo poco útil y necesario establecido en el país a costa de tanto tiempo y trabajo. Llamábase D. Juan Báñez..., y como tales vendió los pertenecientes a los mareantes, llevándose más de 8.000 pesos para su amo, dejando a los pobres nautas canarios en el desamparo que aquí vemos" Loc. citado.

${ }_{87}$ «...que sin embargo de que el Ramo de Pesquería, se considera y ha considerado siempre por el más importante, así porque el pescado salado es en ella y en las otras un abasto de primera necesidad, como porque es el que constituye la única negociación o granjería que se reconoce entre estos naturales". Canaria, 20.5.804. Informe de la Audiencia. Legado citado. 
«el pensamiento es grande, el método, prevenciones y reglas muy oportunas y proporcionadas del ingenio y meditación de su autor» ${ }^{88}$,

no puede al mismo tiempo, dejar de manifestar,

«los estorbos invencibles que impedirían los progresos de unas ideas tan bastas, como ventajosas al parecer ${ }^{89}$,

ya que consideran impracticable su instalación, que además ocasionarían grandes gastos y diligencias inútiles ${ }^{90}$.

Los tres inconvenientes máximos que se ofrecen a los oidores se reducen a: $1 .^{\circ}$, la Cofradía ha consumido con el tiempo el fondo prevenido para constituir el montepio; $2^{\circ}$, en ninguna de las islas se produce ni siquiera uno de los géneros que se proponen elaborar; y $3 .^{\circ}$, los dueños de embarcaciones llamados a actuar como directores y agentes del montepío, carecen de la «instrucción y aptitud necesarias» para realizar «los cálculos de Economía» precisos para el manejo de empresa tan compleja ${ }^{91}$. Realidad, de otra parte, lógica, dado el bajo nivel de educación que reciben los canarios ${ }^{92}$. De semejante situación son conscientes los propios armadores; tanto, que últimamente han comparecido algunos ante la Audiencia, para presentar

88 Documento citado.

89 Informe citado.

90 «...el establecimiento del Montepío es impracticable, atendiendo a las circunstancias destas islas, y que si quisiere llevar adelante, además de que nunca se lograría verle realizado, se malograrian con seguridad cuantos gastos y diligencias se hicieran con semejante designio". Documento citado.

91 «Y para que los rezelos de la Audiencia no aparezcan infundados, basta manifestar a VA que entre todos los dueños de barcos no hay quizás uno que dexe de valerse de persona extraña para que le ajuste la cuenta de los gastos y utilidades que ha tenido la Pesquería en la zafra, que es cuando se entera a los marinos en los que, como partícipes, les toca y tienen que recibir porque muchos de aquellos no saben leer ni escribir, o lo hacen muy mal». Loc. citado.

92 «En una palabra la rusticidad e ignorancia son los accidentes que con más frecuencia se ven en estos naturales, porque la instrucción pública ha estado siempre abandonada y por lo mismo en el día han fixado toda su atención y vigilancia los actuales Ministros en formar expedientes sobre Escuelas Públicas y promover otras que estaban atrasadas". Documento citado. 
«formal solicitud, separándose del seguimiento del expediente, y pidiendo se sobresea" ${ }^{93}$,

por preferir a cambio la protección del Tribunal en la demanda que realizaron ante la Secretaría de Marina para obtener unos estatutos y entrar en dependencia de la jurisdicción de un juez privativo, que recaería en uno de los oidores ${ }^{94}$.

\section{EPILOGO}

El informe de la Audiencia venía a cerrar el largo contencioso, iniciado hacía veinte años ${ }^{95}$. La cofradía de mareantes de San Telmo entraba, después de casi un siglo de crecimiento y desarrollo, en una lenta agonía, aunque hay que reconocer que mantuvo el fuego sagrado de la presencia canaria en el banco sahariano. No era entonces tiempo, ni había lugar, para mejorar el nivel de vida de las familias más pobres de los mareantes. Tampoco se contendría la tendencia a la emigración y la ociosidad. Finalmente, se evanescería con el fracaso, el sueño de introducir en las islas un germen de industrialización.

La verdad es que comenzar por el sector textil, aunque pareciera el más factible presentaba serias dificultades: importación de materias primas y dura competencia de los países europeos. Pero quizás, con el intento hubiera mejorado una artesanía doméstica, que hasta no hace demasiados años suministraba de tejidos a los medios rurales, ofreciendo telas de uso prolongado. Recuérdese la moda de las "chaquetas del país».

93 Documento citado.

94 «...y el Tribunal protexa por los medios que le dicte su prudencia y autoridad la pretensión que tiene entablada de muchos años hace por la Secretaria Universal del Despacho de Marina sobra aprobación de sus ordenanzas y de que se les nombre por Juez o protector a un ministro de esta Audiencia, para que... conozca en todo la Gobernación y Economia del Gremio y en lo contencioso en primera instancia con apelación a este Tribunal». Documento citado.

${ }^{95}$ Dictamen del Fiscal. Madrid, 21.12.804. «Entiendo debe escusarse al Montepío de Mareantes". El 3 de enero pasaba el expediente a la Sala del Consejo, que en 1.3.805 decretaba: «excúsese». Legado citado. 
En este proyecto, como en otras realizaciones suyas, brilló con luz propia la iniciativa original del corregidor ejemplar que fue don Joseph Eguíluz, máxima figura entre los muchos buenos corregidores que durante el setecientos prestaron servicio tanto en Gran Canaria, como en Tenerife-La Palma.

También merece destacarse la importancia y el poder de este grupo de mareantes de San Telmo. Gracias a su eficaz y original gestión del negocio de la salazón, lograron acumular un capital con el que se realizaba una labor social de gran transcedencia, incluso permitió acudir sólidamente en socorro de sus paisanos, y realizar obras de ornato, como el pilar o el ajardinamiento inicial de lo que hoy es el parque de San Telmo. 